\title{
FORUM
}

\section{A Survey of Clinical Pharmacokinetic Studies of 17 Cardiovascular Drugs in Japanese New Drug Approvals Between 2000 and 2007}

\author{
Susumu NAKADE ${ }^{* 1}$ Akinori YAMAUCHI ${ }^{* 1}$ Naoki HONDA*1 \\ Junsaku KITAGAWA $^{* 1}$ Tomoya OHNO*1 Chihiro AMANO*1 \\ Yasuo KODAMA*2 and Mikio OGAWA*1 \\ ${ }^{* 1}$ Pharmacokinetic Research Laboratories, Ono Pharmaceutical Co., Ltd., Ibaraki, Japan \\ ${ }^{* 2}$ Laboratory of Bio-Pharmaceutics, Faculty of Pharmaceutical Sciences, Josai International University, Chiba, Japan
}

\begin{abstract}
We analyzed the current status of clinical pharmacokinetic (PK) studies in new drug applications (NDA) by evaluating 17 cardiovascular (CV) drugs that were approved between 2000 and 2007 in Japan since CV drugs were one of the largest categories to be submitted. All summaries of data had been submitted by applicants and were freely accessible on the website of the Pharmaceuticals and Medical Devices Agency (PMDA). The clinical PK studies were divided into 12 categories : single-dose, multiple-dose, food-effect, elderly, gender difference, mass balance, absolute bioavailability, target patients, liver impairment, renal impairment, drug-drug interaction, and population PK studies. The median number of clinical PK studies per new molecular entity (NME) excluding single-dose, multiple-dose, and food-effect studies was 13.5, and foreign data accounted for $86 \%$ of the study results. A relatively high proportion of PK studies in Japanese subjects were observed in elderly volunteers and target patients ; however, a dependency on foreign data was noted in the other PK study categories. The effect of the guidance "Clinical PK Studies of Pharmaceuticals" by the Ministry of Health, Labour and Welfare on implementation of clinical PK studies could not be fully assessed, since there were only three NMEs approved prior to issuance of the guidance. The median number of clinical PK studies per NME was approximately three times higher for drugs for lifestyle-related diseases than that for other drugs. In recent NDA reviews by the PMDA, the trend to emphasize a relationship between PK and safety with respect to drug-drug interactions and/or special populations was noted.
\end{abstract}

Key words : pharmacokinetics, cardiovascular drug, new drug application, population pharmacokinetics

\section{Introduction}

Clinical pharmacokinetic (PK) studies in Japan have historically consisted mainly of single-dose, multiple-dose, and food effect studies that were essential components of a new drug application (NDA). Meanwhile, PK studies that investigated the properties of compounds such as drugdrug interaction studies, special population PK studies, and population PK studies were not routinely conducted. The utility of PK information had not been sufficiently recognized until the issuance of the ICH-E5 guideline ${ }^{1)}$ in 1998. The guideline brought a concept of bridging strategy and $\mathrm{PK}(\mathrm{PK} / \mathrm{PD})$ data gained prominence in drug development. As the significance of PK in drug development was increasingly recognized, the Ministry of Health, Labour and Welfare (MHLW) of Japan issued the first guidance for clinical PK studies in drug development, "Clinical PK Studies of Pharmaceuticals" (MHLW-PK guidance $)^{2)}$ in 2001. To analyze the current status of clinical PK studies in NDAs, we surveyed 17 cardiovascular (CV) drugs approved between 2000 and 2007 in Japan. $\mathrm{CV}$ drugs were selected due to the predominant number of NDAs submitted to the MHLW.

\section{Summary of $17 \mathrm{CV}$ drugs}

Seventeen CV drugs were approved from January 2000 to December 2007 in Japan (Table 1). All summaries of data submitted by applicants were freely accessible on the website. ${ }^{3)}$ Three NMEs (New Molecular Entities) were approved before (2000-2001) and 12 NMEs were approved after (2002-2007) the MHLW-PK guidance was issued, respectively. Therapeutic drugs for hypertension and hypercholesterolemia (eight NMEs) accounted for approximately half of all NMEs. Table 2 summarizes the implementation of 12 types of clinical PK studies for each NME. For the three basic studies, single-dose, multipledose, and food-effect studies, foreign data were surveyed

Address for correspondence : Susumu Nakade. Pharmacokinetic Research Laboratories, Ono Pharmaceutical Co., Ltd.

17-2 Wadai Tsukuba, Ibaraki 300-4247, Japan

(Manuscript received January 20, 2009 ; revised May 11, 2009 and August 12, 2009 ; accepted August 18, 2009) 
Table 1 List of 17 cardiovascular drugs approved from 2000 to 2007 in Japan

\begin{tabular}{|c|c|c|c|c|c|c|}
\hline No. & Nonproprietary name & Target disease & $\begin{array}{l}\text { Approval } \\
\text { year }\end{array}$ & $\begin{array}{l}\text { Review } \\
\text { status }\end{array}$ & $\begin{array}{l}\text { Bridging } \\
\text { study }\end{array}$ & Mechanism of action \\
\hline 1 & Valsartan & Hypertension & 2000 & Normal & No & Angiotensin II receptor antagonist \\
\hline 2 & Sumatriptan & Migraine & 2000 & Normal & No & Serotonin receptor agonist \\
\hline 3 & Edaravon & Acute cerebral infarction & 2001 & Normal & No & Free radical scavenger \\
\hline 4 & Esmolol hydrochloride & Supraventricular tachyarrhythmia & 2002 & Normal & No & $\beta$ blocker \\
\hline 5 & Telmisartan & Hypertension & 2002 & Normal & No & Angiotensin II receptor antagonist \\
\hline 6 & Landiolol hydrochloride & $\begin{array}{l}\text { Atrial fibrillation, atrial flutter, } \\
\text { sinus tachycardia }\end{array}$ & 2002 & Normal & No & $\beta$ blocker \\
\hline 7 & Pitavastatin calcium & Hypercholesterolemia & 2003 & Normal & No & HMG-CoA reductase inhibitor \\
\hline 8 & Rizatriptan benzoate & Migraine & 2003 & Normal & Yes & Serotonin receptor agonist \\
\hline 9 & Azelnidipine & Hypertension & 2003 & Normal & No & Calcium channel blocker \\
\hline 10 & Sevelamer hydrochloride & Hyperphosphataemia & 2003 & Normal & No & Phosphate binder \\
\hline 11 & Olmesartan medoxomil & Hypertension & 2004 & Normal & No & Angiotensin II receptor antagonist \\
\hline 12 & Bosentan hydrate & Pulmonary arterial hypertension & 2005 & Orphan & Yes & Endothelin-1 receptor antagonist \\
\hline 13 & Rosuvastatin calcium & Hypercholesterolemia & 2005 & Normal & Yes & HMG-CoA reductase inhibitor \\
\hline 14 & Mozavaptan hydrochloride & Hyponatremia & 2006 & Orphan & No & Vasopressin V2 antagonist \\
\hline 15 & Clopidogrel bisulfate & Ischemic cerebrovascular disease & 2006 & Rapid & No & ADP receptor antagonist \\
\hline 16 & Ezetimibe & Hypercholesterolemia & 2007 & Normal & No & $\begin{array}{l}\text { Niemann-Pick C1-like } 1 \text { protein inhib- } \\
\text { itor }\end{array}$ \\
\hline 17 & Eplerenone & Hypertension & 2007 & Normal & No & Aldosterone receptor antagonist \\
\hline
\end{tabular}

The drugs approved only in Japan are indicated in italics.

only if Japanese data were not included. Sevelamer hydrochloride was excluded from the analysis, since it is a nonabsorbable poly-cation polymer, which is not absorbed into systemic circulation after oral administration. The median number of clinical PK studies per NME (excluding the three basic studies) was 13.5. Foreign data accounted for $86 \%$ of the studies.

\section{1) Single and multiple-dose studies}

A single or multiple dose study in healthy young adults was conducted for all NMEs, with the exception of sevelamer. A placebo treatment was included in approximately $70 \%$ of studies, and the median number of subjects administered an active drug per group was six. Only bosentan hydrate was studied in Japanese expatriates and non-Japanese subjects. Many PK analysts have been interested in a method to evaluate dose proportionality of PK parameters because there currently is no universal consensus on a method. Although a power model (one $\mathrm{NME}$ ) and linear model (three NMEs) were used for the statistical evaluation, many NMEs were visually evaluated. The findings indicate that there is difficulty in evaluating dose proportionality from a statistical analysis perspective.

\section{2 ) Food-effect studies}

A food-effect study in healthy young adults was conducted for all oral NMEs, with the exception of sevelamer. All studies were conducted in male subjects, and the median number of subjects was 9 (range 6-20). The effect of food was evaluated by a statistical analysis $(\mathrm{n}=10)$ and a visual assessment $(\mathrm{n}=2)$. Statistical analyses included confidence intervals $(n=5)$, t-tests $(n=3)$, and ANOVA $(\mathrm{n}=2)$.

When developing oral drugs, a food effect study in Japanese subjects is important because of the difference in dietary intake between ethnic groups. However, in the bosentan study, only foreign data from non-Japanese subjects was submitted. The reason for this is unknown but bosentan's orphan status may be a factor.

With the exception of olmesartan medoxomil, for which the effects of both standard and high-fat diets were investigated, the other NMEs only evaluated the effect of a standard diet. There is no MLHW guidance for foodeffects studies similar to those that exist in the United States and the European Union. ${ }^{45}$ According to the regulatory guidance in these regions, the standard trial design and analytical method is defined as a high-fat diet, $\mathrm{n}=12$ or more, and utilizing a confidence interval in the statistical analysis. In general, all food-effect studies in Japan have a similar trial design except for using high-fat diet. 


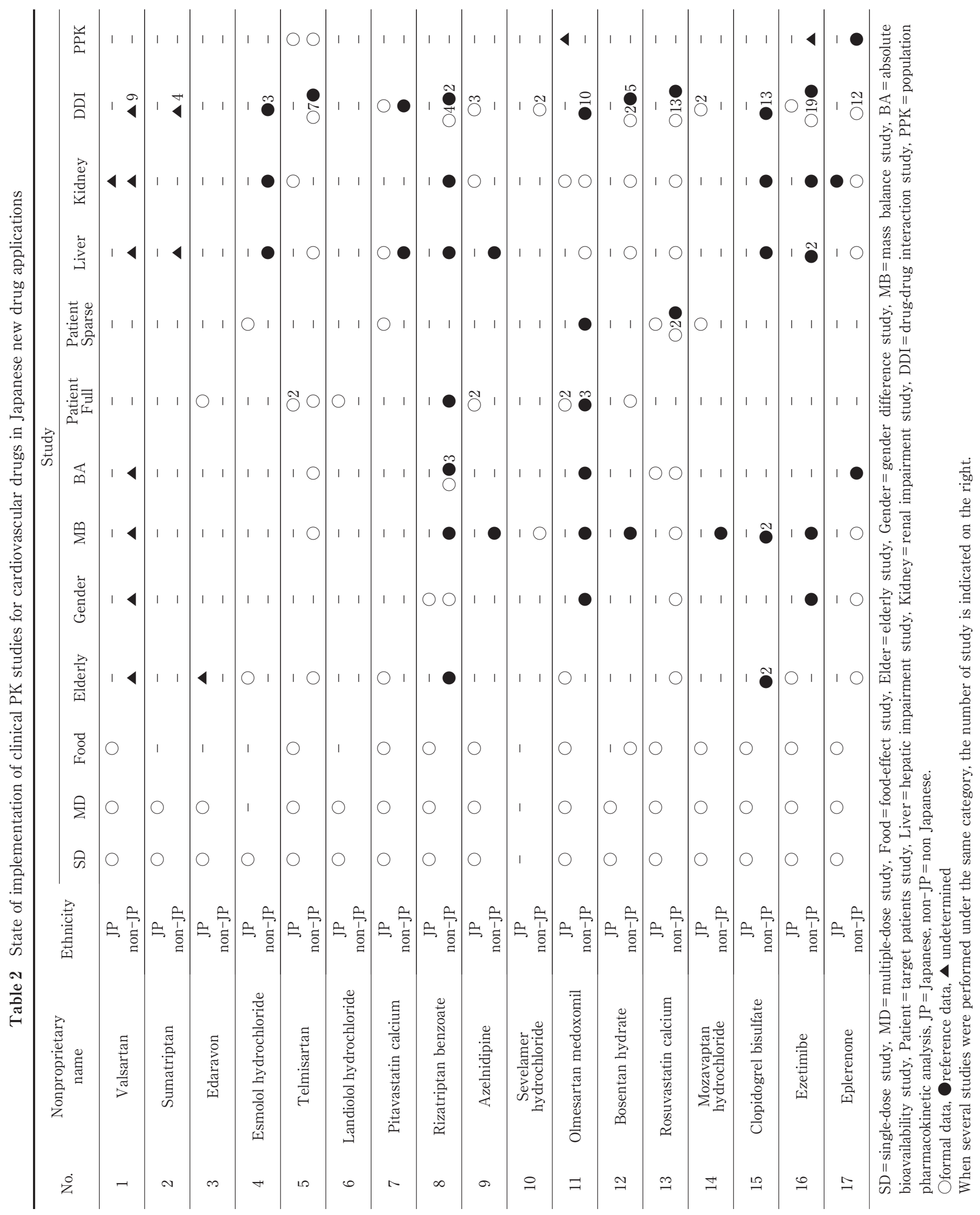




\section{3 ) Elderly PK studies}

Twelve PK studies in healthy elderly subjects were conducted in 11 NMEs (69\%). Five of these were performed in Japanese subjects. With regard to the number of PK studies that specifically included Japanese subjects, elderly PK studies were the second most frequently studied after PK studies in the target population. Six studies included only male subjects while the other five included both male and female subjects, and one was unknown. The median number of subjects per group was 11.5 (5-16). Except for studies involving edaravon and pitavastatin, the effect of age was evaluated based on statistical analyses that included confidence intervals $(n=$ $2)$, t-tests $(\mathrm{n}=1)$, and ANOVA $(\mathrm{n}=3)$.

\section{4) Gender difference PK studies}

Seven studies in six NMEs (38\%) were conducted to evaluate the effect of gender in non-elderly, healthy subjects. Only rizatriptan benzoate was studied in Japanese subjects. This could be because the rizatriptan AUC value in females is approximately 1.3-fold higher than that in males, and most of the target patients were women. The median number of subjects per group was 12 $(8-17)$. The effect of gender was evaluated using confidence intervals $(n=3)$ and ANOVA $(n=3)$.

\section{5 ) Mass balance studies}

Thirteen mass balance studies were conducted in 11 NMEs (69\%), none of which were conducted in Japanese subjects. All studies, with the exception of that involving sevelamer, were conducted in male subjects. The sevelamer study included young and elderly male and female subjects. The combination of different age and gender groups suggests that an extensive mass balance study was conducted for sevelamer to demonstrate its characteristic as a nonabsorbable drug.

\section{6) Absolute bioavailability studies}

Ten absolute bioavailability studies were conducted in six NMEs (38\%). Only rosuvastatin calcium was studied in both Japanese and non-Japanese subjects, while others evaluated non-Japanese subjects only. The rosuvastatin PK results showed that its plasma concentrations in Japanese subjects were approximately two times higher than those in non-Japanese subjects. Thus, absolute bioavailability was key component of the bridging strategy in the new drug development of rosuvastatin in Japan.

\section{7 ) Target patients PK studies}

A total of 14 full PK studies in patients with the target disease were conducted in seven NMEs $(44 \%)$. There were two types of PK evaluations : stand-alone tests $(n=$ 10) in which pharmacokinetics were evaluated in human pharmacology studies and add-on tests $(n=3)$ in which the pharmacokinetics was evaluated as part of therapeutic exploratory or confirmatory studies (one study was unknown). PK evaluation using sparse sampling was performed for eight studies of five NMEs (31\%). The majority of the studies evaluated trough concentrations during repeated administration. The pharmacokinetics in Japanese patients (regardless of whether full PK or sparse sampling was done) was evaluated in nine NMEs (56\%). Target patient PK studies had the highest proportion of Japanese data among all clinical PK studies, excluding the three basic studies. Each of the four NMEs (landiolol hydrochloride, pitavastatin calcium, azelnidipine, and mozavaptan hydrochloride) approved only in Japan, evaluated PK in Japanese patients. In many cases of domestic drug development, clinical PK data, particularly in healthy subjects or special populations, has been limited (Table 2). Our analysis determined that the difficulties in conducting certain studies such as liver impairment studies resulted in a higher tendency to evaluate the PK in target patients.

\section{8 ) Hepatic and renal impairment PK studies}

Fifteen PK studies in patients with hepatic impairment were conducted in 13 NMEs (81\%). Only pitavastatin was studied in Japanese subjects. Since recruiting subjects is difficult, it is rare to conduct a hepatic impairment PK study in Japanese subjects. Although hepatic impairment PK studies were not included in the original NDA package of pitavastatin or azelnidipine, the study results were submitted as additional data during their respective NDA reviews. Fourteen PK studies in patients with renal impairment were conducted in 11 NMEs (69\%). Five NMEs (valsartan, telmisartan, azelnidipine, olmesartan, and eplerenone) included data from Japanese subjects. These five NMEs are all therapeutic drugs for hypertension. This can be attributed to the issuance of ICH-E12A "Principles for Clinical Evaluation of New Antihypertensive Drugs", in which PK studies in hypertensive patients with renal impairment is an essential requirement.

\section{9 ) Drug-drug interaction studies}

A total of 114 drug-drug interaction studies were conducted in 15 NMEs (94\%). Seven studies in four NMEs (pitavastatin, azelnidipine, mozavaptan, and ezetimibe) were performed in Japanese subjects. The studies conducted in Japan have a common feature in that either the NME or the concomitant drug is a domestic drug that is not approved in western countries. Although the drugdrug interaction studies were not included in the original NDA packages for pitavastatin or azelnidipine, the study 
Table 3 List of concomitant drugs in drug-drug interaction studies

\begin{tabular}{|c|c|c|}
\hline Nonproprietary name & $\begin{array}{l}\text { Major elimination pathway } \\
\text { or major metabolic enzymes }\end{array}$ & Concomitant drugs \\
\hline Valsartan & Bile excretion & $\begin{array}{l}\text { amlodipine, atenolol, cimetidine, digoxin, furosemide, hydrochlorothiazide, } \\
\text { indomethacin, glibenclamide, warfarin, }\end{array}$ \\
\hline Sumatriptan & Monoamine oxidase A & alcohol, flunarizine, moclobemide, propranolol, selegiline \\
\hline Esmolol hydrochloride & Esterase & digoxin, morphine, warfarin \\
\hline Telmisartan & Bile excretion & $\begin{array}{l}\text { amlodipine, digoxin, glibenclamide, hydrochlorothiazide, ibuprofen, parace- } \\
\text { tamol, simvastatin, warfarin, }\end{array}$ \\
\hline Pitavastatin calcium & Bile excretion & cyclosporine, fenofibrate, gemfibrozil \\
\hline Rizatriptan benzoate & Monoamine oxidase A & $\begin{array}{l}\text { ergotamine, metoprolol, moclobemide, nadolol, oral contraceptive, paroxe- } \\
\text { tine, propranolol }\end{array}$ \\
\hline Azelnidipine & CYP3A4 & grapefruit juice, itraconazole, $\underline{\text { simvastatin }}$ \\
\hline Sevelamer hydrochloride & - & digoxin, enalapril, metoprolol, warfarin \\
\hline Olmesartan medoxomil & Bile excretion & $\begin{array}{l}\text { amlodipine, antacid, atenolol, atorvastatin, digoxin, glibenclamide, hydro- } \\
\text { chlorothiazide, pravastatin, simvastatin, warfarin }\end{array}$ \\
\hline Bosentan hydrate & CYP2C9, 3A4 & $\begin{array}{l}\text { cyclosporine, digoxin, glibenclamide, ketoconazole, oral contraceptive, } \\
\text { simvastatin, warfarin }\end{array}$ \\
\hline Rosuvastatin calcium & Bile excretion & $\begin{array}{l}\text { antacid, cyclosporine, digoxin, erythromycin, fenofibrate, fluconazole, } \\
\text { gemfibrozil, itraconazole, ketoconazole, oral contraceptive, warfarin }\end{array}$ \\
\hline Mozavaptan hydrochloride & CYP3A4 & dextromethorphan, itraconazole \\
\hline Clopidogrel bisulfate & CYP3A4, 1A2, 2C19, 2B6 & $\begin{array}{l}\text { antacid, antipyrine, atenolol, aspirin, cimetidine, digoxin, enalapril, estrogen, } \\
\text { heparin, naproxen, nifedipine, phenobarbital, theophylline, warfarin, }\end{array}$ \\
\hline Ezetimibe & Bile excretion & $\begin{array}{l}\text { antacid, atorvastatin, cerivastatin, cholestyramine, cimetidine, cyclosporine, } \\
\text { digoxin, fenofibrate, fluvastatin, gemfibrozil, glipizide, intravenous probe } \\
\text { (midazolam), lovastatin, oral probe (caffeine, tolbutamide, dextromethor- } \\
\text { phan, diamino diphenyl sulfone), oral contraceptive, pitavastatin, pravasta- } \\
\text { tin, rosuvastatin, simvastatin, warfarin }\end{array}$ \\
\hline Eplerenone & CYP3A & $\begin{array}{l}\text { antacid, clarithromycin, cyclosporine, digoxin, erythromycin, fluconcazol, } \\
\text { grapefruit juice, ketoconazol, midazolam, oral contraceptive, saquinavir, } \\
\text { simvastatin, St Jones' wart, verapamil, warfarin }\end{array}$ \\
\hline
\end{tabular}

The studies conducted in Japanese subjects are underlined.

Results of drug-drug interaction studies were not included in landiolol and edaravon NDAs.

results were submitted as additional data during their respective NDA reviews. The median number of drugdrug interaction studies per NME was 7 (2-21). Table 3 lists the concomitant drugs used in these interaction studies for each NME. Digoxin and warfarin were the most frequently administered concomitant drugs and both drugs are recommended in the ICH-E7 guideline "Studies in Support of Special Populations : Geriatrics”. ${ }^{6}$ Following these two drugs, simvastatin was the next most frequently administered concomitant drug. This might be attributed to the fact that simvastatin is often coadministrated with $\mathrm{CV}$ drugs and is a substrate of CYP3A4.

\section{0) Population PK studies}

Five population PK analyses were performed in four
NMEs (25\%). Of these, two NMEs included Japanese data in the population PK analysis. This rate of population PK analysis is comparable to that of all NDAs submitted between 1999 and $2006(16.4 \%)^{8)}$

\section{1) Pharmacogenomic studies}

The effect of cytochrome P450 gene polymorphisms was not assessed. For rosuvastatin, the relations between plasma drug concentrations and OATP-C (oganic anion transport polypeptide C) gene polymorphism was assessed in Japanese patients $(\mathrm{n}=39)$ and foreign patients $(n=264)$ to investigate the basis of ethnic differences. OATP-C is a transporter that functions to enhance hepatic uptake of rosuvastatin, as well as pravastatin and simvastatin. ${ }^{9,10)}$ OATP-C gene polymorphism, however, 
Table 4 Effect of the MHLW-PK guidance and target disease on the implementation of clinical PK studies

\begin{tabular}{|c|c|c|c|c|c|c|c|c|c|c|}
\hline & Elderly $^{\mathrm{a}}$ & Gender $^{\mathrm{a}}$ & $\mathrm{MB}^{\mathrm{a}}$ & $\mathrm{BA}^{\mathrm{a}}$ & $\begin{array}{l}\text { Patient } t^{\mathrm{a}} \\
\text { (full) }\end{array}$ & $\begin{array}{l}\text { Patient }{ }^{\mathrm{a}} \\
\text { (sparse) }\end{array}$ & Liver $^{a}$ & Kidney $^{\mathrm{a}}$ & $\mathrm{DDI}^{\mathrm{a}}$ & $\mathrm{PPK}^{\mathrm{a}}$ \\
\hline $\begin{array}{l}\text { Before MHLW-PK } \\
\text { guidance }(2000-2001)\end{array}$ & $1 / 2 / 3$ & $0 / 1 / 3$ & $0 / 1 / 3$ & $0 / 1 / 2$ & $1 / 1 / 3$ & $0 / 0 / 3$ & $0 / 2 / 3$ & $1 / 1 / 3$ & $0 / 2 / 3$ & $0 / 0 / 3$ \\
\hline $\begin{array}{l}\text { After MHLW-PK } \\
\text { guidance }(2002-2007)\end{array}$ & $4 / 9 / 13$ & $1 / 5 / 13$ & $0 / 10 / 13$ & $1 / 5 / 11$ & $4 / 6 / 13$ & $4 / 5 / 13$ & $1 / 11 / 13$ & $4 / 10 / 13$ & $3 / 12 / 13$ & $2 / 4 / 13$ \\
\hline $\begin{array}{l}\text { Hypertension \& } \\
\text { Hypercholesterolemia } \\
\text { (Lifestyle-related disease) }\end{array}$ & $3 / 7 / 8$ & $0 / 5 / 8$ & $0 / 7 / 8$ & $1 / 5 / 8$ & $3 / 3 / 8$ & $2 / 3 / 8$ & $1 / 8 / 8$ & $5 / 7 / 8$ & $3 / 8 / 8$ & $2 / 4 / 8$ \\
\hline Other diseases & $2 / 4 / 8$ & $1 / 1 / 8$ & $0 / 4 / 8$ & $0 / 1 / 5$ & $2 / 4 / 8$ & $2 / 2 / 8$ & $0 / 5 / 8$ & $0 / 4 / 8$ & $1 / 6 / 8$ & $0 / 0 / 8$ \\
\hline
\end{tabular}

${ }^{a}$ Elder = elderly study, Gender = gender difference study, $\mathrm{MB}=$ mass balance study, BA = absolute bioavailability study, Patient $=$ target patients study, DDI = drug-drug interaction study, Liver = hepatic impairment study, Kidney = renal impairment study, PPK = population pharmacokinetic analysis. A number in these columns indicates the number of NMEs conducting Japanese study/the total number of NMEs conducting the concerned study/the number of target NMEs.

was not related to plasma rosuvastation concentrations in this study. This pharmacogenomic investigation may be conducted to support the basis for successful bridging, as well as in the evaluation of ethnic differences in bioavailability.

\section{2) Effect of the MHLW-PK guidance and target disease on the implementation of clinical PK studies}

We compared the trends of clinical PK studies before and after issuance of the MHLW-PK guidance, and between drugs for lifestyle-related disease (hypertension and hypercholesterolemia) and other drugs (Table 4). The median number of clinical PK studies per NME (excluding the three basic studies) before and after the guidance was 5 (2-16) and 16 (1-28), respectively. However, since there were only three NMEs that were approved before the MHLW guideline, the effect of MHLW-PK guidance could not be fully assessed. Meanwhile, the number of NMEs of drugs for lifestyle-related disease and other drugs, except for sevelamer, was almost equivalent, 7 and 8 , respectively. Among drugs for lifestyle-related disease, the median number of clinical PK studies per NME was approximately three times higher than that of other drugs. Clinical PK studies of drugs for lifestyle-related diseases were more likely to include Japanese subject data than PK studies for other types of drugs. Long-term administration and polypharmacy are the characteristics of drugs for lifestyle-related disease. Therefore, to assure safety under conditions of wideranging clinical use, a large number of clinical PK studies will continue to be required for these drugs.

13) PK-related Issues in NDA review

Based on the assessment report by the Pharmaceuticals and Medical Devices Agency (PMDA), we categorized the inquiries from the PMDA regarding clinical PK. The noteworthy inquiries were as follows : drug-drug interaction (15 NMEs), administration to patients with hepatic (11 NMEs) and renal impairment (six NMEs). Drug-drug interactions in the main metabolic pathway or main excretion route and/or interaction with frequently administered concomitant drugs were requested in many cases. Inquiries referring to hepatic and renal impairment were to require answers regarding PK and safety considerations and their relevance to labeling. Other issues frequently raised were the effects of age and/or gender on PK and safety (five NMEs) and the relationship between food effect and labeling (five NMEs). Race differences in $\mathrm{PK}$ were investigated for rizatriptan and rosuvastatin among the three NMEs that were approved based on the bridging strategy.

\section{Summary and future directions}

We surveyed 12 types of clinical PK studies of $17 \mathrm{CV}$ drugs that were approved in Japan between 2000 and 2007. Although the effect of the MHLW-PK guidance on clinical PK studies could not be fully assessed, we found that the NDA package varies widely, depending in part on whether the drug is targeted for a life style-related disease or not. A relatively high proportion of elderly PK studies and target patient PK studies included analyses for Japanese subjects. Other PK study categories were largely dependent on foreign data. This might have been to avoid difficulties associated with the conduct of clinical pharmacological studies in Japan or to prevent data duplication. Until further guidance, it seems likely that future NDAs will remain largely based on foreign PK data. As a result, it 


\begin{tabular}{cc}
\hline $\begin{array}{c}\text { Number of total studies } \\
\text { NME Median (Range) }\end{array}$ & $\begin{array}{c}\text { Foreign studies/ } \\
\text { Total studies }\end{array}$ in all NMEs \\
\hline $5(2-16)$ & $20 / 23(87 \%)$ \\
$16(1-28)$ & $156 / 186(84 \%)$ \\
$19(6-28)$ & $119 / 144(83 \%)$ \\
$6(1-19)$ & $57 / 65(88 \%)$ \\
\hline
\end{tabular}

${ }^{\mathrm{b}}$ When several studies were performed under the same category, all of them were counted.

will continue to be difficult for Japanese physicians to find data for new drugs based on specialized Japanese populations such as those with liver or kidney impairments. One way to bolster Japanese PK data could be to design population PK studies added on long term administration studies. Thus, informative data can be collected in some special populations such as the elderly, both gender, and patients with mild liver or renal impairment. NDA review by the PMDA may have a better outcome if the sponsor proactively evaluates the relationship between PK and safety on drug-drug interaction and/ or special population. Moreover, population PK studies are also attractive with respect to cost and development speed, since they are add-on studies and do not require the conduct of separate or additional clinical studies. In the case of drug approved based on a bridging strategy, Japanese postmarketing studies are more important because Japanese data, especially safety data, is not perfect. Population PK analyses will be a powerful tool for characterizing safe and efficacious therapeutic doses of new drugs for target populations. What is essential is that a sufficient amount of PK data is collected to allow appropriate dosing for patients and to help regulatory agencies and pharmaceutical companies better inform patient populations.

\section{References}

1) International Conference on Harmonization of Technical Requirements for Registration of Pharmaceuticals for Human Use. ICH Harmonized Tripartite Guideline : Ethnic Factors in the Acceptability of Foreign Clinical Data. E5. Available from : URL : http://www. ich. org/LOB/media/MEDIA481. pdf Accessed April 1, 2009.

2) Minister of Health and Labour Welfare (MHLW). Guidance for industry : Clinical Pharmacokinetic Studies of Pharmaceuticals [in Japanese]. 2001. Available from : URL : http://www.nihs.go. jp/mhlw/tuuchi/2001/010601-796/010601-796. pdf Accessed April 1, 2009.

3) Pharmaceuticals and Medical Devices Agency (PMDA). Information on new drug approvals [in Japanese]. Available from : URL : http://www.info.pmda.go.jp/shinyaku/shinyaku_index. html Accessed April 1, 2009.

4) Food and drug administration. Guidance for industry : Foodeffect bioavailability and fed bioequivalence studies. Available from : URL : http://www.fda.gov/downloads/Drugs/Guidan ceComplianceRegulatoryInformation/Guidance/ucm070241.pdf

5) The European Agency for the Evaluation of Medical Products. Note for guidance on the investigation of bioavailability and bioequivalence. Available from : URL : http://www.emea.europa. eu/pdfs/human/qwp/140198enfin. pdf Accessed April 1, 2009.

6) International Conference on Harmonization of Technical Requirements for Registration of Pharmaceuticals for Human Use. ICH Harmonized Tripartite Guideline : Studies in Support of Special Populations : Geriatrics. E7. Available from : URL : http:// www. ich. org/LOB/media/MEDIA483. pdf Accessed April 1, 2009.

7) Neuvonen PJ, Niemi M, Backman JT. Drug interactions with lipid-lowering drugs : mechanisms and clinical relevance. Clin Pharmacol Ther. $2006 ; 80: 565-81$.

8) Nakade S, Kitagawa J, Higashi R, Hasegawa C, Nakane H, AMANO C, et al. A survey of population pharmacokinetic study on new drug applications in Japan. JPN J TDM. $2009 ; 26: 21-7$.

9) Kitamura S, Maeda K, Wang Yi, Sugiyama Y. Involvement of multiple transporters in the hepatobiliary transport of rosuvastatin. Drug Metab Dispos. $2008 ; 36: 2014-23$.

10) Kameyama Y, Yamashita K, Kobayashi K, Hosokawa M, Chiba K. Functional characterization of SLCO1B1 (OATP-C) variants, SLCO1B1 ${ }^{*} 5$, SLCO1B1 ${ }^{*} 15$ and SLCO1B1 ${ }^{*} 15+\mathrm{C} 1007 \mathrm{G}$, by using transient expression systems of HeLa and HEK293 cells. Pharmacogenet Genomics. 2005 ; 15 : 513-22. 